
SUPPORTING INFORMATION:

2 Monitoring the collapse of $\mathrm{pH}$-sensitive liposomal

3 nanocarriers and environmental $\mathrm{pH}$ simultaneously

4

5

6

7

8

9

10
- a fluorescence based approach
Sören Draffehn and Michael U. Kumke*

University of Potsdam, Institute of Chemistry (Physical Chemistry),

Karl-Liebknecht-Str. 24-25, 14476 Potsdam-Golm, Germany

*e-mail: kumke@uni-potsdam.de, Tel.: +49 331977 5209, Fax: +49 3319775058 
1 Table SI1. Fluorescence decay times of the different analyzed dyes incorporated in

2 DOPE/CHEMS or POPC liposomes and incubated for $\sim 12$ hours under physiological or 3 acidic conditions.

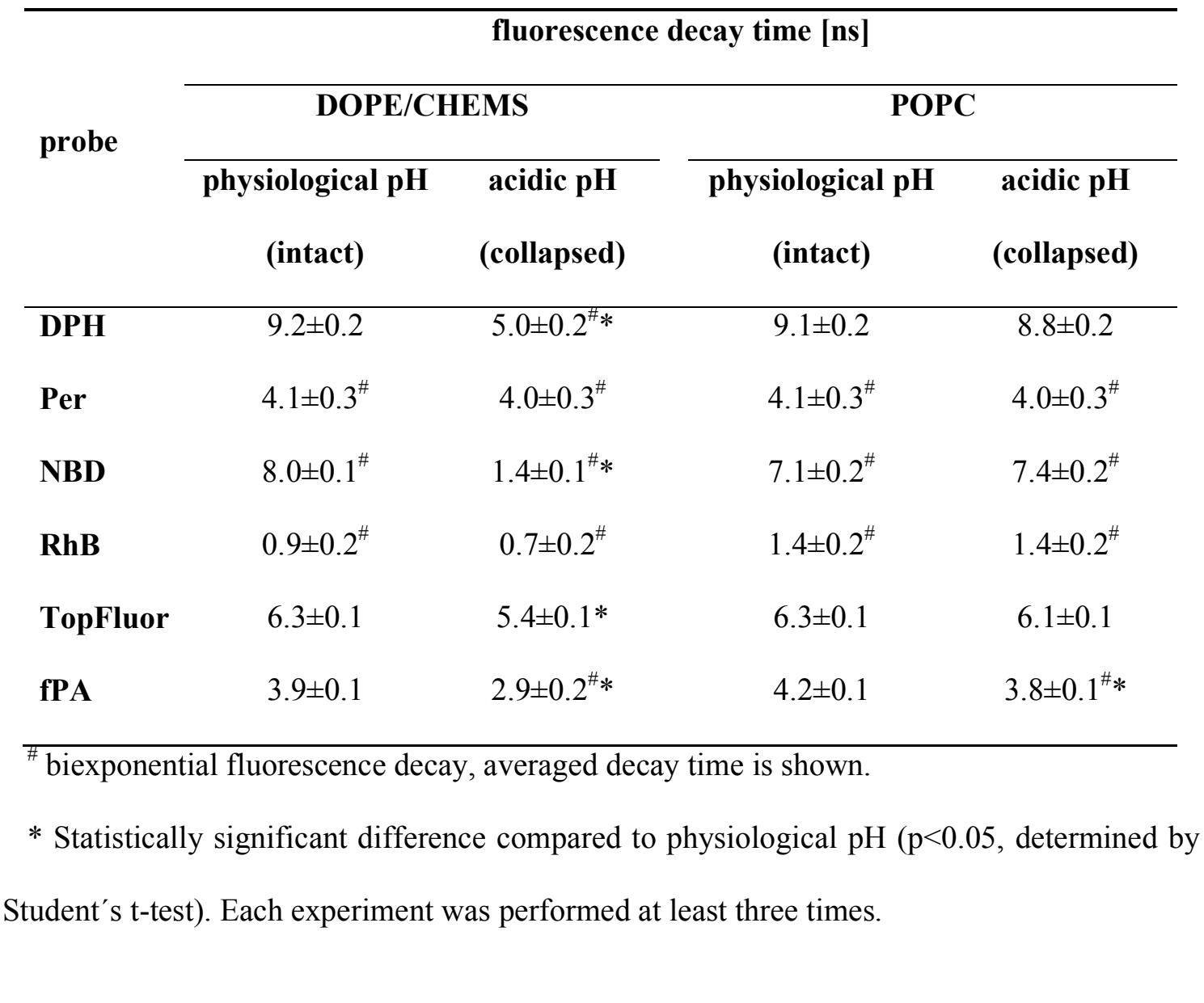


1 Table SI2. Fluorescence anisotropy of the different analyzed dyes incorporated in 2 DOPE/CHEMS or POPC liposomes and incubated for $\sim 12$ hours under physiological or 3 acidic conditions.

\section{fluorescence anisotropy}

\begin{tabular}{|c|c|c|c|c|}
\hline \multirow{2}{*}{ probe } & \multicolumn{2}{|c|}{ DOPE/CHEMS } & \multicolumn{2}{|c|}{ POPC } \\
\hline & $\begin{array}{c}\text { physiological pH } \\
\text { (intact) }\end{array}$ & $\begin{array}{l}\text { acidic pH } \\
\text { (collapsed) }\end{array}$ & $\begin{array}{c}\text { physiological pH } \\
\text { (intact) }\end{array}$ & $\begin{array}{l}\text { acidic pH } \\
\text { (collapsed) }\end{array}$ \\
\hline DPH & $0.24 \pm 0.02$ & $0.03 \pm 0.04 *$ & $0.17 \pm 0.02$ & $0.19 \pm 0.03$ \\
\hline Per & $0.27 \pm 0.01$ & $0.03 \pm 0.04 *$ & $0.27 \pm 0.01$ & $0.27 \pm 0.01$ \\
\hline NBD & $0.04 \pm 0.01$ & $0.01 \pm 0.01 *$ & $0.05 \pm 0.01$ & $0.07 \pm 0.01 *$ \\
\hline RhB & $0.04 \pm 0.01$ & $0.04 \pm 0.01$ & $0.03 \pm 0.01$ & $0.03 \pm 0.01$ \\
\hline TopFluor & $0.08 \pm 0.01$ & $0.07 \pm 0.01$ & $0.07 \pm 0.01$ & $0.08 \pm 0.01$ \\
\hline fPA & $0.23 \pm 0.01$ & $0.07 \pm 0.02 *$ & $0.2 \pm 0.01$ & $0.27 \pm 0.01 *$ \\
\hline \multicolumn{5}{|c|}{ * Statistically significant difference compared to physiological $\mathrm{pH}(\mathrm{p}<0.05$, determined by } \\
\hline Student's & Each experimen & performed & hree times. & \\
\hline
\end{tabular}




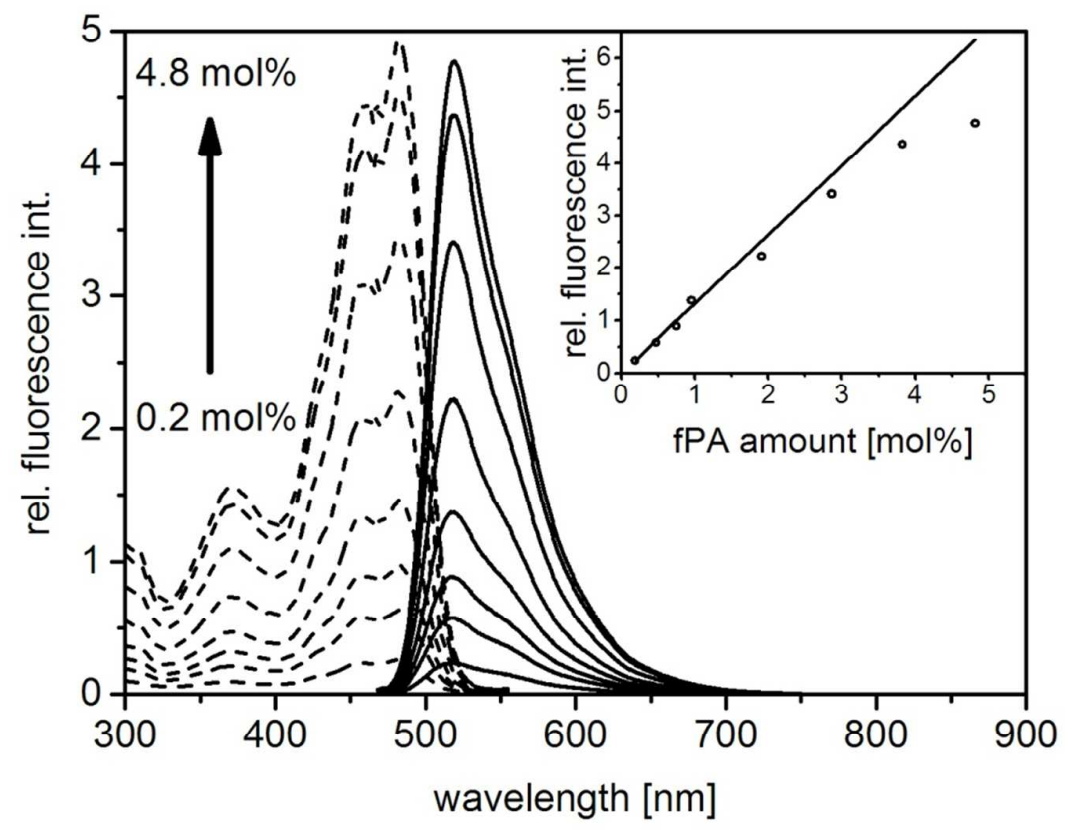

2

3 Figure SI1. Fluorescence excitation (dashed lines) and emission spectra (solid lines) of fPA

4 incorporated in DOPE/CHEMS liposomes at $\mathrm{pH}$ 6.92. The amount of fPA was increased from

$5 \quad 0.2$ to $4.8 \mathrm{~mol} \%(0.5$ to $12 \mu \mathrm{M})$. The samples were incubated for $\sim 12$ hours. The inset shows

6 the relative fluorescence intensity of the maxima of the emission spectra as a function of the

7 incorporated dye amount.

8

9 
1 Table SI3. Particle sizes of DOPE/CHEMS and POPC liposomes determined by FCS and

2 DLS after incubation for $\sim 12$ hours at physiological or acidic $\mathrm{pH}$ conditions.

\begin{tabular}{llccc}
\hline \multirow{2}{*}{ liposome } & pH & \multicolumn{2}{c}{ particle size [nm] } \\
\cline { 3 - 3 } & & FCS & DLS \\
\hline DOPE/CHEMS & physiological & $94 \pm 16$ & & $68 \pm 21$ \\
DOPE/CHEMS & acidic & $2 \pm 1^{*}$ & & $1 \pm 1^{*}$ \\
POPC & physiological & $83 \pm 6$ & & $54 \pm 14$ \\
POPC & acidic & $74 \pm 6$ & & $57 \pm 14$
\end{tabular}

$3 *$ Statistically significant difference compared to physiological $\mathrm{pH}(\mathrm{p}<0.05$, determined by 4 Student's t-test). Each experiment was performed at least three times.

5

6

7

8

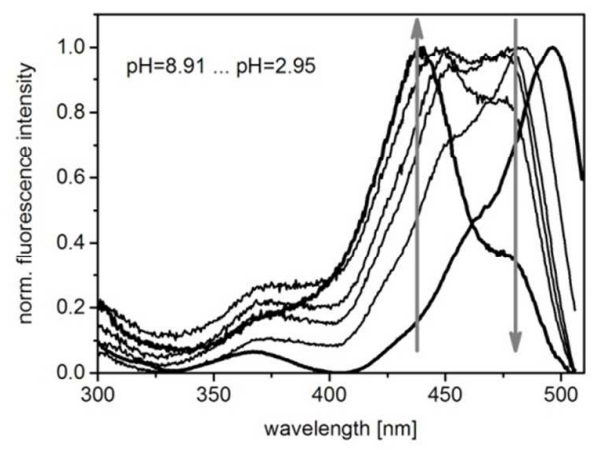

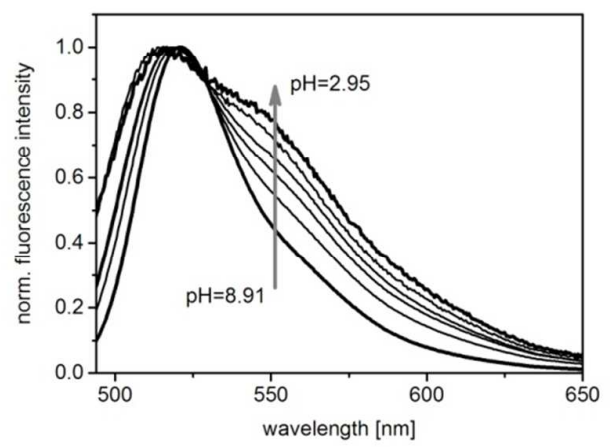

9 Figure SI2. (left) Fluorescence excitation spectra and (right) emission spectra of fPA 10 incorporated in DOPE/CHEMS liposomes as a function of the $\mathrm{pH}$. The amount of fPA was $110.5 \mathrm{~mol} \%(1.25 \mu \mathrm{M})$. The samples were incubated for $\sim 12$ hours in a buffer system adjusted 12 to certain $\mathrm{pH}$. The gray arrows indicate the change in the spectra with decreasing $\mathrm{pH}$. 


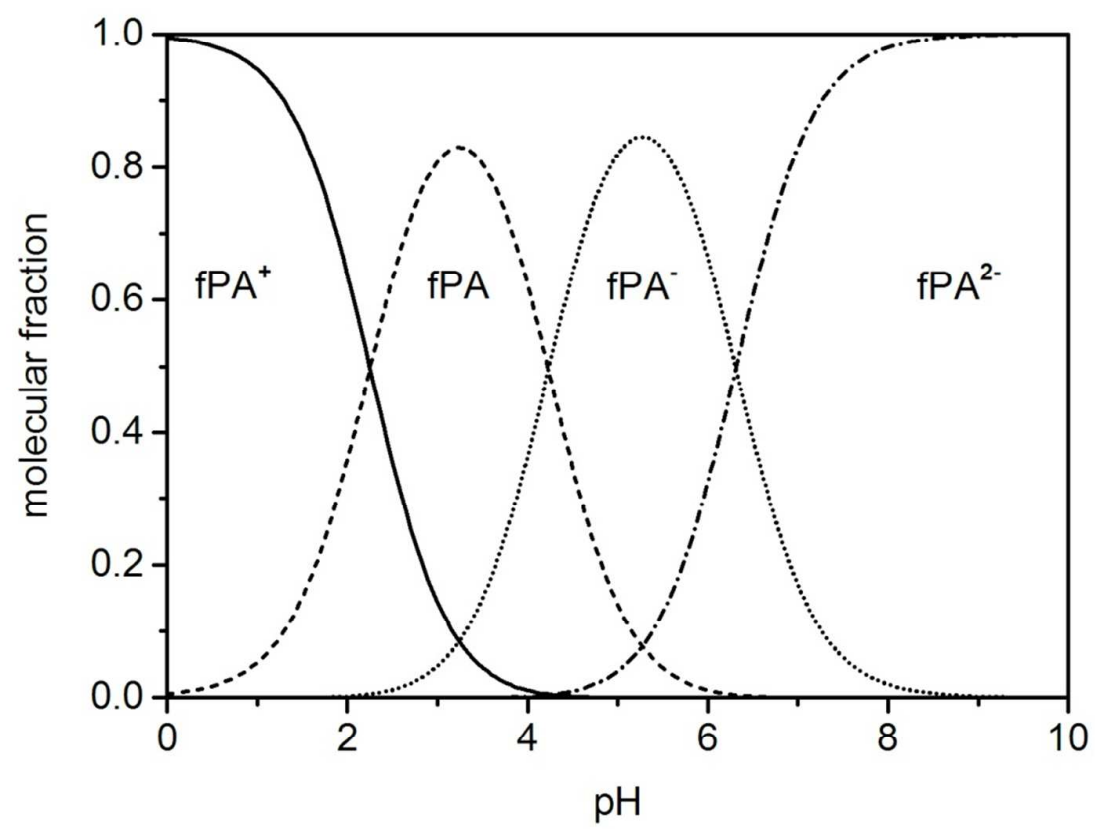

2 Figure SI3: Molecular fraction of the protolytic species of fPA depending on the $\mathrm{pH}$.

3 Cationic $-\mathrm{fPA}^{+}$(solid), neutral $-\mathrm{fPA}$ (dashed), anionic $-\mathrm{fPA}^{-}($dotted $)$, dianionic $-\mathrm{fPA}^{2-}$

4 (dash-dotted). These fractions were calculated based on the $\mathrm{p} K_{\mathrm{a}}$ values from ref. 1. 


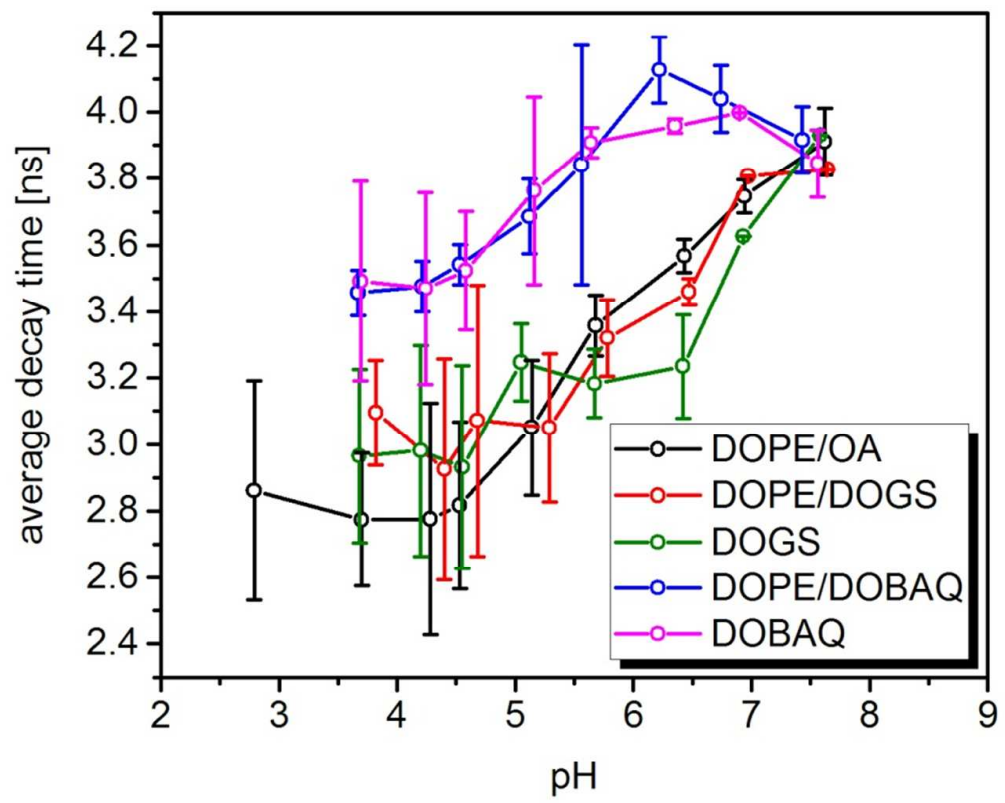

2

3 Figure SI4. Dependency of the fluorescence decay time of fPA incorporated in different 4 pHSLips on the pH: DOPE/OA, DOPE/DOGS, DOGS, DOPE/DOBAQ, and DOBAQ. The 5 concentration of fPA was $0.5 \mathrm{~mol} \%(1.25 \mu \mathrm{M})$. The samples were incubated for $\sim 12$ hours in 6 a buffer system adjusted to certain $\mathrm{pH}$.

8 REFERENCES

9 (1) Klonis, N.; Sawyer, W. H. Spectral Properties of the Prototropic Forms of Fluorescein in Aqueous Solution. J. Fluoresc. 1996, 6 (3), 147-157. 